\title{
Construção e validação de podcast com conteúdo educacional em saúde com
} participação ativa de acadêmicos de enfermagem

Construction and validation of podcast with educational content in health with active participation of nursing students

Construcción y validación de podcast con contenido educativo en salud con participación activa de estudiantes de enfermeira

Recebido: 07/03/2021 | Revisado: 14/03/2021 | Aceito: 17/03/2021 | Publicado: 23/03/2021

Ricardo Alexandre Amaral Muniz

ORCID: https://orcid.org/ 0000-0003-4935-2552 Múltiplos Saberes, Brasil

E-mail: ricardoamaral1@yahoo.com.br

Paolo Porciúncula Lamb

ORCID: https://orcid.org/0000-0002-6712-0168

Secretaria da Saúde de Recife, Brasil

E-mail: paoloplamb@gmail.com

Andréa Loureiro Roges

ORCID: https://orcid.org/0000-0003-0109-2114

Secretaria da Saúde de Recife, Brasil

E-mail: deiaroges@hotmail.com

Ednaldo Cavalcante de Araújo

ORCID: https://orcid.org/0000-0002-1834-4544

Universidade Federal de Pernambuco, Brasil E-mail: ednenjp@gmail.com

Eliane Maria Ribeiro de Vasconcelos ORCID: https://orcid.org/0000-0003-3711-4194

Universidade Federal de Pernambuco, Brasil E-mail: emr.vasconcelos@gmail.com

Vilma Célia Amaral Muniz

ORCID: https://orcid.org/0000-0002-4580-3056

Secretaria da Educação de Recife, Brasil

E-mail:vcamara10455@gmail.com

\begin{abstract}
Resumo
Objetivo: Descrever a construção e validação de um podcast educacional em saúde com participação ativa de acadêmicos de enfermagem. Método: Estudo metodológico desenvolvido em duas etapas. Na primeira etapa foi construído um podcast educacional com acadêmicos de enfermagem. Utilizando o gênero peça radiofônica para promoção da saúde em hanseníase. Na segunda o podcast foi submetido à validação de conteúdo por 22 juízes especialistas multidisciplinares das áreas de saúde, comunicação, educação e tecnologia educacional. Os dados foram analisados no software SPSS ${ }^{\circ}$ Statistics, versão 20.0, sendo realizado o cálculo do I-IVC Índice de Validade de Conteúdo. Resultados: O IVC apresentou-se acima de 0,80 e a concordância foi satisfatória na maioria dos itens. Quanto à relevância, 25 de 30 itens tiveram I-IVC acima de 0,80 entre os juízes, considerando-o adequado para utilização em ações de educação em saúde. Os cinco itens abaixo de 0,80 foram alterados, conforme as sugestões. Considerações finais: Construir e validar o podcast educacional de forma participativa permitiu que os discentes conhecessem uma ferramenta educacional em formato de áudio, e a peça radiofônica como uma forma lúdica de levar conteúdos educacionais, permitindo visualizar que é possível elaborar e difundir conteúdos educacionais pautada na dialogicidade, em que os diversos atores envolvidos são protagonistas na produção e difusão de conteúdos.
\end{abstract}

Palavras-chave: Podcast; Validação; Participação ativa; Ensino.

\begin{abstract}
Objective: To describe the construction and validation of an educational podcast in health with active participation of nursing academics. Method: Methodological study developed in two stages. In the first stage an educational podcast was built with nursing academics. Using the genre radiophonic piece to promote health in leprosy. In the second, the podcast was submitted to content validation by 22 multidisciplinary experts from the areas of health, communication, education and educational technology. The data were analyzed in the software SPSS ${ }^{\circ}$ Statistics, version 20.0, and the I-IVC Content Validity Index was calculated. Results: IVC was above 0.80 and concordance was satisfactory in most items. Regarding relevance, 25 of 30 items had I-IVC above 0.80 among judges, considering it adequate for use in
\end{abstract}


health education actions. The five items below 0.80 have been changed as suggested. Conclusion: Building and validating the educational podcast in a participatory manner allowed the students to know an educational tool in audio format, and the radio piece as a playful way of carrying educational contents, allowing to visualize that it is possible to elaborate and disseminate educational contents based on the dialogicity, in which the various actors involved are protagonists in the production and diffusion of contents.

Keywords: Podcast; Validation; Active participation; Teaching.

\section{Resumen}

Objetivo: Describir la construcción y validación de un podcast educativo en salud con la participación activa de estudiantes de enfermería. Método: Estudio metodológico desarrollado en dos etapas. En una primera etapa se construyó un podcast educativo con estudiantes de enfermería. Utilización del género teatral radiofónico para la promoción de la salud en la lepra. En el segundo, el podcast fue sometido a validación de contenido por 22 jueces expertos multidisciplinarios en las áreas de salud, comunicación, educación y tecnología educativa. Los datos se analizaron mediante el software SPSS $®$ Statistics, versión 20.0, con el cálculo del Índice de Validez de Contenido IIVC. Resultados: El CVI estuvo por encima de 0,80 y la concordancia fue satisfactoria en la mayoría de los ítems. En cuanto a la relevancia, 25 de los 30 ítems tenían I-CVI por encima de 0,80 entre los jueces, considerándolo apto para su uso en acciones de educación en salud. Los cinco elementos por debajo de 0,80 se cambiaron, como se sugirió. Consideraciones finales: La construcción y validación del podcast educativo de manera participativa permitió a los estudiantes descubrir una herramienta educativa en formato de audio, y el juego de radio como una forma lúdica de acercar contenidos educativos, permitiéndoles visualizar que es posible elaborar y difundir contenidos educativos basados en la dialogicidad, en los que los distintos actores involucrados son protagonistas en la producción y difusión de contenidos.

Palabras clave: Podcast; Validación; Participación activa; Ensenãnza.

\section{Introdução}

O advento e a popularização das tecnologias via web abrem uma nova fronteira e propiciam uma ruptura do "monopólio" na produção, difusão e uso da informação. Os meios de comunicação e a tecnologia têm uma forte influência na formação crítica do cidadão seja mudando as linguagens ou as formas de transmissão e os processos de armazenamento dos dados (Sganzerlla, 2011). As tecnologias cada vez mais convergem combinando aparatos tecnológicos e novas nomenclaturas para novas formas de comunicação e de aquisição, armazenamento, processamento, produção e distribuição de informação. Sua importância cresce cada vez mais na sociedade e propicia redefinição das relações de produção e de poder (Ruiz, 2002). Essas características e contradições da sociedade influenciam gradativamente o cotidiano afetando a forma como se aprende, se ensina e nas formas de participação nas questões de uma sociedade que se apresenta em constante mudança e se organiza e reorganiza de acordo com características de uma sociedade em rede e globalizada (Castells \& Espanha, 2007).

Com todas essas mudanças na sociedade e nas tecnologias, o rádio e a difusão de áudio também ultrapassaram as fronteiras da radiodifusão. A transmissão não se limita mais a transmissores terrestres; satélites ou cabo (Meditsch, 2001). A internet é a nova fronteira. A transmissão de programas deixa de ser exclusiva dos poucos estúdios de rádio e passa para a web através de podcasts e outras tecnologias que permitem que cada indivíduo seja um transmissor de conteúdo, permitindo desta forma responder ao clamor por informação e participação da sociedade.

Apesar do meio de transmissão ser diferente, algumas das funções do rádio (Mcleish, 2001), são mantidas na transmissão de áudio pela web, entre elas, a mínima exigência tecnológica, dispensando todo o aparato comum nos meios visuais (câmera, luzes e outros recursos). Basta uma estrutura simples para construir e divulgar conteúdo em áudio pela web, sendo os custos relativamente baratos, se comparados com outros meios de comunicação, tanto do ponto de vista de investimento quanto de manutenção (Mcleish, 2001). Na transmissão por áudio as palavras e a forma de falar são pensadas para o ouvinte com suas particularidades e expectativas (Mcleish, 2001), permitindo que as pessoas se expressem de diferentes maneiras. Sendo a linguagem, por si só, um instrumento de interação entre o pensamento humano e o seu meio.

O áudio pela web mantém a função do rádio como "pano de fundo" (Mcleish, 2001) possuindo uma ligação mais tênue com o usuário permitindo ao ouvinte fazer outras atividades ao mesmo tempo em que escuta a transmissão. O áudio 
transmitido via rádio ou via web tem a capacidade de ensinar, pois funciona bem no mundo das ideias, formando "imagens" do tamanho da imaginação do ouvinte, sendo estas formadas a partir de efeitos sonoros apropriados, música adequada, e a entonação da narração (Mcleish, 2001). Servindo para veicular qualquer assunto que possa ser discutido, conduzindo o ouvinte, num ritmo predeterminado, por um conjunto de informações (Mcleish, 2001). A transmissão via web possui uma vantagem em relação à transmissão por rádio, pois o mesmo rompe com a efemeridade do meio, pode-se ouvir o programa quando quiser mesmo que já tenha sido transmitido (Mcleish, 2001).

A transmissão por áudio carrega consigo uma função social desde que surgiu vem se firmando como um serviço de utilidade pública (Mcleish, 2001; Bertolli Filho, 2011). Vem deixando como legado princípios como ação, atuação, transformação e mobilização. Ajuda a desenvolver objetivos comuns e opções políticas, possibilitando o debate social e político e expondo temas e soluções práticas atuando como agente de informação e formação do coletivo.

\section{Metodologia}

Estudo metodológico com abordagem quantitativa (Pereira et., 2018) para descrever a construção e validação de um podcast educacional. A pesquisa foi aprovada pelo Comitê de Ética e Pesquisa, da UFPE, com parecer $n^{\circ}: 1660.670$. (CAAE: 57173316.6.0000.5208) atendendo às normas previstas pela Resolução 466/2012 do Conselho Nacional de Saúde - Ministério da Saúde. O estudo foi desenvolvido em duas etapas. Na primeira etapa do estudo foi construído um podcast educacional para promoção da saúde em hanseníase. Elaborado e construído de forma participativa com acadêmicos de enfermagem da Universidade Federal de Pernambuco (UFPE), que participaram de forma voluntária de todas as etapas de formação e discussão para elaboração do podcast educacional, Os mesmos, se apresentaram como sujeitos ativos na produção de conteúdo educacional em saúde de forma participativa. Utilizou-se gênero peça radiofônica para aproximar a informação a ser transmitida e a visão cultural e cientifica dos participantes.

$\mathrm{Na}$ segunda etapa o podcast foi submetido à validação de conteúdo por 22 juízes especialistas multidisciplinares das áreas de saúde, comunicação, educação e tecnologia educacional. Foram enviados formulários eletrônicos e disponibilizado o áudio para que os mesmos avaliassem criticamente o podcast. Os dados referentes às apreciações dos juízes obtidos mediante análise dos instrumentos de validação do conteúdo foram passados para uma planilha eletrônica Microsoft Excel e exportada para o software Statistical Package for the Social Science (SPSS) version 20.0 for Windows onde foi realizada sua análise. Para análise dos dados e validação dos instrumentos, foi realizado o cálculo do Índice de Validade de Conteúdo (IVC). Este mostra a congruência da opinião dos juízes especialistas por meio da proporção de concordância sobre os aspectos do instrumento que se pretende validar. Para cada item da escala foi atribuído um valor numérico de forma que para as opções "concordo totalmente" e "concordo" sendo atribuído o valor +1 , por se tratarem de avaliações positivas; para a opção "nem concordo nem discordo" foi atribuído o valor 0 (zero) por se tratar de uma opção neutra e para as opções "discordo" e "discordo totalmente" foi atribuído o valor -1, por se tratar de uma opção de avaliação negativa. A partir destes valores o IVC foi calculado mediante as seguintes vertentes (Polit \& Beck, 2011):

- I-CVI (Item-level Content Validity Index): corresponde à quantidade de juízes que concordaram ou concordaram totalmente com determinado item. Foi calculado, para cada item, mediante a soma do número de juízes que atribuíram respostas de pontuação +1 . O valor resultante desta soma foi dividido pelo número total de juízes, obtendo-se assim a proporção de concordância entre os juízes.

- S-CVI (Scale-level Contente Validity Index): corresponde à média aritmética da proporção dos itens que receberem avaliação de concordo ou concordo totalmente do total de juízes.

Foi considerado como aprovado na validação o item que obteve I-CVI maior ou igual a 0,80 e S-CVI maior ou igual a 0,90 sendo este o coeficiente de validade (Polit \& Beck, 2011). 
Considerando que seria de relevância a sugestão de mudanças dos juízes o instrumento de validação constou com espaços para considerações e sugestões dos avaliadores. As falas apreendidas foram uteis para entender em qual contexto o item não aprovado precisaria melhorar.

Após a validação de conteúdo da primeira versão da tecnologia educacional proposta os resultados foram analisados e as sugestões consideradas apropriadas foram incorporadas e realizados os ajustes necessários, resultando na versão final da tecnologia educacional.

\section{Resultados}

O podcast educacional "A Mancha" foi construído por sete alunos de graduação em enfermagem da UFPE, 85,7\% $(n=6)$ cursando o $8^{\circ}$. Período e $14,3 \%(n=1)$ cursando o $6^{\circ}$. Período que fazem parte do grupo de pesquisa em comunicação e educação em saúde (50\%), educação em saúde (25\%) e outros grupo na área de saúde (25\%). Os mesmos costumam utilizar tecnologias educacionais para produzir seus trabalhos acadêmicos, sendo o mais utilizado a mídia impressa (35,3\%), na sequência o vídeo $(29,4 \%)$, o áudio $(17,6 \%)$ e apresentações por slide (17,6\%). Também costumam produzir conteúdos educacionais em saúde utilizando a mídia impressa $(41,7 \%)$, o áudio $(25 \%)$, o vídeo $(16,7 \%)$ e o slide $(16,7 \%)$ para suas ações. Quando perguntado se produzem ou já produziram podcasts e/ou áudio para web $57,1 \%(n=4)$ já o fizeram, sendo $75 \%(n=3)$ com conteúdo de entretenimento e $25 \%(\mathrm{n}=1)$ com conteúdo educacional. Os mesmos também consomem o conteúdo produzido na web, $77,7 \%$ costumam ouvir áudios, sejam educacionais $(33,3 \%)$ ou para entretenimento $(44,4 \%)$. E a plataforma mais utilizada é o youtube e o facebook com $40 \%$ cada e o whatsapp com $20 \%$. Percebeu-se que a pouca familiaridade com a produção de conteúdo educacional em áudio não foi uma barreira difícil de transpor, uma vez que os mesmos concluíram com êxito todas as etapas, desde sua concepção até fase de masterização, para produção do podcast educacional em hanseníase sendo disponibilizado tal produto com dezoito minutos de duração para validação dos juízes especialista multidisciplinares.

$\mathrm{Na}$ etapa de validação de conteúdo vinte e dois juízes com graduação em Enfermagem 45,5\% (n=10), Comunicação social/Rádio e $\operatorname{Tv}$ 31,8\% (n=7), Comunicação Social/ Jornalismo 13,6\% (n=3) e Educação 9,1\% (n=2). Que atuam profissionalmente na área de Saúde pública 45,5\% (n=10), Comunicação social 27,3\% (n=6) e tecnologia da informação e comunicação 27,3\% (n=6). Destes 77,3\% tem experiência em docência, nas áreas de Saúde pública e/ou educação em saúde 52,9\% ( $\mathrm{n}=9$ ), na área de tecnologia na educação e/ou áudio e/ou rádio 29,4\% (n=5), na área de comunicação social 11,8\% $(\mathrm{n}=2)$ e na área de enfermagem 5,9\% (n=1). Destes 63,6\% (n=14) são mestres e 22,7\% (n=5) são doutores, sendo suas áreas de estudo nas dissertações e/ou teses em saúde pública e/ou saúde coletiva 35,3\% (n=6), em comunicação social 35,3\% (n=6), em mídias digitais 11,8\% ( $\mathrm{n}=2)$, em tecnologias na educação $(\mathrm{n}=2)$ e em educação em saúde 5,9\% (n=1).

A média do I-CVI (Item-level Content Validity Index) para o podcast educacional foi de 0,89. Já o S-CVI (Scale-level Contente Validity Index) que corresponde à média aritmética da proporção dos itens que receberem avaliação de concordo ou concordo totalmente do total de juízes foi igual a 0,90. Quanto a relevância dos itens, expressa pelo cálculo do I-CVI (Itemlevel Content Validity Index), que corresponde à quantidade de juízes que concordarem ou concordarem totalmente com determinado item. Verifica-se que o valor do I-CVI foi maior do que 0,80 na maioria dos itens avaliados, exceto para os itens 2.2, 2.5, 3.3, 3.8 e 3.9 conforme Tabela 1. 
Tabela 1 - Itens para validação do podcast educacional, segundo os juízes. Recife, 2016.

\begin{tabular}{l|c}
\hline & I-CVI \\
\hline 1.1 O conteúdo atende uma possível situação de educação em saúde. & 1,00 \\
\hline 1.2 O conteúdo é coerente com uma prática educacional em saúde. & 0,95 \\
\hline 1.3 O conteúdo é relevante para educação em saúde & 1,00 \\
\hline 1.4 O podcast mostra aspectos culturais da realidade da população sobre a hanseníase & 0,91 \\
\hline 1.5 O podcast consegue transmitir informação educacional em saúde para diferentes públicos & 0,86 \\
\hline 1.6 O podcast é esclarecedor sobre a hanseníase & 1,00 \\
\hline 1.7 O conteúdo é claro e objetivo & 0,95 \\
\hline 1.8 O gênero peça radiofônica auxiliou na transmissão do conteúdo & 0,95
\end{tabular}

$2.1 \mathrm{O}$ podcast é fácil de ser acessado.

$2.2 \mathrm{~A}$ abertura do podcast chama a atenção de quem está ouvindo e indica sobre o conteúdo do material.

2.3 A linguagem utilizada está compatível com um material educacional

$2.4 \mathrm{O}$ podcast é adequado para difusão de material educacional em saúde

3.1 O título chama a atenção do ouvinte

3.2 O título é coerente com o conteúdo

3.3 A duração do podcast é satisfatória para fornecer conhecimento sobre a hanseníase

$3.4 \mathrm{O}$ formato de peça radiofônica motiva a ouvir o podcast

$3.5 \mathrm{O}$ conteúdo e a história apresentadas incentiva a conhecer/entender sobre a hanseníase

3.6 As cenas são simples e claras e abordam o conhecimento sobre a hanseníase

3.7 Existe lógica na sequência da narrativa

$3.8 \mathrm{O}$ ouvinte é incentivado a prosseguir a audição do conteúdo até o final

0,91

3.9 A formulação dos diálogos é atrativa e não cansativa

1,00

4.1 Os cenários e personagens são atraentes e identificáveis pela voz (locução) e pelos efeitos sonoros utilizados

4.2 Os efeitos sonoros, o tipo de locução e as trilhas sonoras selecionadas facilitam o entendimento do podcast.

4.3 É fácil perceber a mudança de personagem pelo tom da voz e tipo de locução.

4.5 Os personagens estão bem caracterizados pelo tom de voz (locução) e pelos efeitos sonoros utilizados.

4.6 A trilha/efeitos sonoros auxiliou no entendimento do conteúdo

4.7 A trilha/efeitos sonoros auxiliou na ambientação dos espaços

Fonte: Autores (2017).

As sugestões emitidas nos itens que tiveram I-CVI abaixo de 0,80, para melhoria do podcast educacional, foram referentes à abertura do podcast (item 2.2), o tempo do podcast (item 2.5), a duração do podcast (item 3.3), sobre incentivo a continuar a ouvir (item 3.8) e sobre a formulação do diálogo (item 3.9). Sendo modificados todos os itens, correlacionando a avaliação com as sugestões deixadas por muitos dos juízes ficou claro que o fato da abertura ser pouco atraente se dava ao fato 
de haver um diálogo longo para apresentação da trama, sendo os demais itens que ficaram abaixo de 0,80 se deve a esse fato o tempo ficar muito longo com diálogos que poderiam ser suprimidos, pois não fariam grande diferença para a trama. Após a avaliação dos juízes o podcast educacional foi reformulado, suprimindo as falas que não comprometeriam as ideias centrais e secundarias propostas sendo as mesmas preservadas, ao final do processo o podcast educacional ficou com doze minutos de duração.

\section{Discussão}

A construção de um podcast educacional utilizando o gênero peça radiofônica (Mcleish, 2001; Prado, 2012) que é um produto sonoro que envolve teatro, literatura e música, onde a intenção é ir além da simples narração de uma história, busca construir uma dramatização sonora onde o som transmite uma história (Mcleish, 2001; Consani, 2012; Prado, 2012) de modo criativo para discussão de temas do cotidiano (Amarante, 2012) ${ }^{10}$. A dramaturgia em áudio, e posteriormente em vídeo, desde seus primórdios contribuíram no aspecto da saúde, pautando muitas vezes, assuntos que de alguma forma são tabus na sociedade. Um exemplo disso é a introdução na dramaturgia do tema preservativo após o aparecimento da AIDS contribuindo assim na prevenção de doenças (Hansen, 2004). Para construção de uma peça radiofônica é interessante perceber que ela está ligada mutuamente a outras formas de expressão como a música, o teatro e a literatura (Montagnari, 2004).

Construir e validar um podcast com conteúdos educacionais em saúde produzidos de forma crítica e reflexiva por acadêmicos de enfermagem possibilita que os sujeitos participantes tenham autonomia, sendo parte integrante da construção de sua história, de sua cultura e de sua educação, reconhecendo e tomando consciência sobre sua situação de opressão social (Freire, 1996), de sua situação de sujeito negado em uma realidade social injusta e desigual permitindo-se perceber como sujeito de direito em uma prática reflexiva onde repetições a partir de padrões pré definidos podem ser modificados a partir do olhar sobre a realidade, sendo a problematização um ponto de partida para esta mudança e de uma grande importância para construção do conhecimento em saúde (Torrezan, Guimarães, \& Furlanetti, 2012).

A problematização e o diálogo podem levar os indivíduos a uma melhor compreensão da realidade, conhecendo melhor sua realidade ele pode modificá-la (Freire, 1996) e a partir do momento que ele modifica fazendo parte do processo e das tomadas de decisão o sujeito caminha para uma participação cidadã (Arnstein, 1969). O preceito de promoção à saúde sobre a participação e utilizando metodologias participativas com base na autonomia dos sujeitos e do diálogo visto em Freire ${ }^{13}$ foi construído o podcast no formato de uma peça radiofônica, visando principalmente destacar a participação efetiva da pessoa humana, sendo o técnico um mero facilitador do processo. Desta forma destaca-se que o produto construído tem como principal finalidade não apenas servir como um material educacional em saúde sobre a temática da hanseníase, mas apresentar o rádio/podcast como uma ferramenta de fácil participação e construção pelos participantes podendo ser utilizada facilmente com escolares de qualquer idade e em qualquer faixa etária com requisitos mínimos para desenvolver a ação. Sendo a peça radiofônica uma ferramenta que ilustra situações do cotidiano do público, usado para facilitar a compreensão do conteúdo e estabelecer empatia com o ouvinte (Mcleish, 2001; Freire, 2013); trabalha conflitos, sentimentos, motivações e é capaz de dar leveza à narrativa radiofônica. Fator importante, especialmente, em programas com temas científicos (Mcleish, 2001).

Depois de submetido a juízes especialistas multidisciplinares para avaliar o podcast educacional em quatro dimensões (conteúdo, aparência, funcionalidade e ambiente sonoro) o mesmo obteve o Índice de Validade de Conteúdo (IVC) = 0,89, sendo considerado validado. Individualmente cada uma das dimensões também foi validado com escores acima de 0,80 , apresentando os seguintes escores: quanto ao conteúdo (IVC $=0,95$ ), quanto à aparência (IVC $=0,82$ ), quanto à funcionalidade $(\mathrm{IVC}=0,86)$ e quanto ao ambiente sonoro $(\mathrm{IVC}=0,95)$. A dimensão com menor escore foi o da aparência sendo os itens relacionados ao tempo final do podcast e a duração de alguns diálogos os que receberam menores escores, pois os juízes referiram em seus comentários que o mesmo ficou bastante longo tornando o mesmo cansativo. As sugestões emitidas 
nestes itens para melhoria do podcast educacional foram modificadas suprimindo falas que não interferiam para o entendimento da trama. Sendo o podcast reformulado, suprimindo as falas que não comprometeriam as ideias centrais e secundarias propostas sendo as mesmas preservadas, ao final do processo o podcast educacional que inicialmente tinha dezoito minutos de duração ficou com doze minutos ao final.

Um dos critérios que obtiveram escores bem elevados foi o conteúdo (IVC=0,95), que demonstra a qualidade da informação transmitida e o ambiente sonoro (IVC=0,95) que é de grande relevância para uma mídia em áudio e para um peça radiofônica, uma vez que nas dramatizações vozes diferentes; acordes dramáticos; música; sons e ruídos assumem diferentes funções e dão brilho e variedade a uma peça radiofônica (Freire, 2013). Sendo um dos principais objetivos de todo texto dramático ter as ideias originais recriadas na mente dos ouvintes (Mcleish, 2001).

Para as modificações a partir da análise dos dados dos instrumentos de avaliação dos juízes especialistas foi discutido com o grupo e realizada uma nova edição das falas, sem perda para o conteúdo dos temas centrais: Hanseníase (sinais, sintomas e tratamento); sensibilizar para uma doença que é tratável; Mostrar o tratamento como um direito do cidadão; Importância da informação e do conhecimento; Importância e função social de uma rádio comunitária; Importância da USF, do enfermeiro e do ACS nesse contexto; nem houve perda dos temas secundários, os quais a ruptura de estereótipo de gênero (onde a mulher sempre é apresentada como dona de casa); a valorização da função social da comunicação e o papel da rádio comunitária; a importância do tratamento completo da hanseníase; discutir o acesso ao medicamento e ao serviços de saúde não como uma gratuidade e sim um direito; além de cuidados e prevenção sobre a hanseníase, ficando desta forma a versão final em 12 minutos.

Ter um podcast construído de forma totalmente horizontal e validado por juízes especialistas multidisciplinares contribui para que os processos educacionais sejam eles através de tecnologias ou não, leve a uma reflexão no modo de fazer educação em saúde onde o outro, seja um aluno, seja um comunitário seja visto como um sujeito que possui um conhecimento e não um "saco vazio" (Freire, 1996) promover processos educacionais que busquem a ação-reflexão (Polit \& Beck, 2011) com todos os atores envolvidos deve ser algo que deve caminhar sempre juntas (Furlanetti, 2009).

Ao concluir o estudo e passado por toda etapas de produção do podcast educacional percebeu-se que a pouca familiaridade com a produção de conteúdo educacional em áudio não foi uma barreira difícil de transpor, uma vez que a prática em áudio e a forma como se fala através dele expressa proximidade e intimidade (Santos, 2012) com a prática cotidiana de cada sujeito falar, o que contribuiu para o trabalho em equipe e a elaboração do radiodrama. Mostrando desta forma ao grupo participante que a ferramenta podcast pode ser vista como uma ferramenta de colaboração entre diversos atores e que permite multiplicar e aumentar a difusão de informações em saúde. E que os mesmos possam produzir materiais educacionais em saúde utilizando esta tecnologia. Construindo os mesmos de forma participativa com o público ao qual se destinam seus conteúdos e que as práticas para produção de conteúdos educacionais visualizando a dramaticidade de uma peça radiofônica como uma ferramenta é propícia para captar a atenção do ouvinte nas temáticas cotidianas que podem auxiliar em um processo de educação em saúde.

\section{Conclusão}

O presente estudo apresentou a validação do uso de um Podcast educacional como instrumento de aproximação da Enfermagem diante uma estratégia educacional desenvolvida de forma participativa e compartilhada entre todos os agentes envolvidos, evidenciando uma produção de saberes dialógica fomentando o cultivo da promoção à saúde. Através do processo educacional participativo, buscou-se possibilitar a promoção da saúde através do uso do recurso do áudio, destacando o tema da Hanseníase apresentado em caráter educacional, informativo e socialmente relevante. 
A importância de se validar um podcast enquanto tecnologia educacional, construído a partir dos repertórios dos envolvidos, correlacionando os saberes populares e científicos permite legitimar o exercício da cidadania e autonomia dos sujeitos envolvidos, possibilita a expressão do ser social além de fortalecer uma ruptura do poder e da centralização na transmissão de informação centrada apenas em um mediador.

Validar um podcast com conteúdo educacional permitiu também validar a expressão oral conhecida historicamente pela mídia rádio como um importante difusor de informação e comunicação. Construir um conteúdo educacional de forma participativa possibilitou visualizar que processos comunicacionais executados de forma horizontalizada aproxima e integra realidades e necessidades.

Considera-se, portanto, a necessidade da abrangência da construção e do uso da ferramenta tecnológica podcast como recurso educacional, que venha a contribuir para aproximar os saberes e emponderar os sujeitos envolvidos, fomentando novas formas e novos olhares para a promoção em saúde.

\section{Referências}

Amarante, M. I. (2012). Rádio Comunitária na Escola. Adolescentes, dramaturgia e participação cidadã. Intermeios.

Arnstein, S. R. (1969). A ladder of citizen participation. Journal of the American Institute of planners, 35(4), 216-224. https://doi.org/10.1080/01944366908977225

Bertolli Filho, C. (2011). História da saúde pública no Brasil. In História da saúde pública no Brasil (pp. 72-72).

Castells, M., \& Espanha, R. (2007). A era da informação: economia, sociedade e cultura. Fundação Calouste Gulbenkian. Serviço de Educação e Bolsas.

Consani, M. (2012). Como usar o rádio na sala de aula. (2a ed.). Editora Contexto.

Freire, E. P. A. (2013). Conceito educativo de podcast: um olhar para além do foco técnico. Educação, Formação \& Tecnologias. 6(1), 35-51.

Freire, P. (1996). Pedagogia da autonomia: saberes necessários à pratica educativa. Paz e Terra.

Furlanetti, M. P. D. F. R. (2009). Compartilhando experiências: dialogando com a prática da alfabetização. Canal6.

Hansen, J. H. (2004). Como entender a saúde na comunicação. Paulus.

Mcleish, R. (2001). Produção de rádio: um guia abrangente da produção radiofônica. Summus.

Meditsch, E. (2001). O ensino do radiojornalismo em tempos de internet. In Congresso Nacional De Comunicação-Intercom (GT Rádio e Mídia Sonora), 24, $1-10$.

Montagnari, E. F. (2004). Rádio e teatro: memória e possibilidades. Acta Scientiarum. Human and Social Sciences, 26(1), 145-149. https://doi.org/10.4025/actascihumansoc.v26i1.1570

Pereira, A. S. et al. (2018). Metodologia da pesquisa científica. UFSM. https://repositorio.ufsm.br/bitstream/handle/1/15824/Lic_Computacao_MetodologiaPesquisa-Cientifica.pdf?sequence $=1$.

Polit, D. F., \& Beck, C. T. (2011). Fundamentos de pesquisa em enfermagem: avaliação de evidências para a prática da enfermagem. Artmed Editora.

Prado, M. (2012). História do rádio no Brasil. Da Boa Prosa.

Ruiz, O. L. (2002). Manuel Castells e a "era da informação”. Jornal Com-Ciência, www. comciencia. com. br.

Santos C.A., \& Ota D. C. (2012). Retextualização no rádio: a oralidade e a escrita no meio eletrônico. Comunicação \& Mercado/UNIGRAN, 1(2), 130-42.

Sganzerlla S. (2011) Rádios Web e educação: comunicação protagonista na formação do cidadão (Dissertação de mestrado). Universidade Federal da Bahia, Salvador, BA, Brasil.

Torrezan, R. M., Guimarães, R. B., \& Furlanetti, M. P. D. F. R. (2012). A importância da problematização na construção do conhecimento em saúde comunitária. Trabalho, Educação e Saúde, 10(1), 107-124. http://dx.doi.org/10.1590/S1981-77462012000100007 